\title{
The total solar eclipse of March 2006: overview
}

\author{
E. Gerasopoulos ${ }^{1}$, C. S. Zerefos ${ }^{1}$, I. Tsagouri ${ }^{1}$, D. Founda ${ }^{1}$, V. Amiridis ${ }^{1}$, A. F. Bais ${ }^{2}$, A. Belehaki ${ }^{1}$, N. Christou ${ }^{3}$, \\ G. Economou ${ }^{4}$, M. Kanakidou ${ }^{5}$, A. Karamanos ${ }^{4}$, M. Petrakis ${ }^{1}$, and P. Zanis ${ }^{6}$ \\ ${ }^{1}$ National Observatory of Athens, V. Pavlou and I. Metaxa, P. Penteli, 15236, Athens, Greece \\ ${ }^{2}$ Laboratory of Atmospheric Physics, Physics Department, Aristotle University of Thessaloniki, Thessaloniki, Greece \\ ${ }^{3}$ Institute of Oceanography, Hellenic Center for Marine Research, Athens, Greece \\ ${ }^{4}$ Laboratory of Agronomy, Faculty of Plant Production, Agricultural University of Athens, Athens Greece \\ ${ }^{5}$ University of Crete, Chemistry Department, Environmental and Chemical Processes Laboratory, Crete, Greece \\ ${ }^{6}$ Department of Meteorology and Climatology, Aristotle University of Thessaloniki, Thessaloniki, Greece
}

Received: 1 November 2007 - Published in Atmos. Chem. Phys. Discuss.: 10 December 2007

Revised: 1 August 2008 - Accepted: 5 August 2008 - Published: 3 September 2008

\begin{abstract}
This paper provides the overview of an integrated, multi-disciplinary effort to study the effects of the 29 March 2006 total solar eclipse on the environment, with special focus on the atmosphere. The eclipse has been visible over the Eastern Mediterranean, and on this occasion several research and academic institutes organised co-ordinated experimental campaigns, at different distances from eclipse totality and at various environments in terms of air quality. Detailed results and findings are presented in a number of component scientific papers included in a Special Issue of Atmospheric Chemistry and Physics. The effects of the eclipse on meteorological parameters, though very clear, were shown to be controlled by local factors rather than the eclipse magnitudes, and the turbulence activity near surface was suppressed causing a decrease in the Planetary Boundary Layer. In addition to the above, the decrease in solar radiation has caused change to the photochemistry of the atmosphere, with night time chemistry dominating. The abrupt "switch off" of the sun, induced changes also in the ionosphere (140 up to $220 \mathrm{~km}$ ) and the stratosphere. In the ionosphere, both photochemistry and dynamics resulted to changes in the reflection heights and the electron concentrations. Among the most important scientific findings from the experiments undertaken has been the experimental proof of eclipse induced thermal fluctuations in the ozone layer (Gravity Waves), due to the supersonic movement of the moon's shadow, for the first time with simultaneous measurements at three altitudes namely the troposphere, the stratosphere and the ionosphere.
\end{abstract}

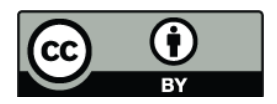

Correspondence to: E. Gerasopoulos (egera@meteo.noa.gr)
Within the challenging topics of the experiments has been the investigation of eclipse impacts on ecosystems (field crops and marine plankton). The rare event of a total solar eclipse provided the opportunity to evaluate 1 dimensional (1-D) and three dimensional (3-D) radiative transfer (in the atmosphere and underwater), mesoscale meteorological, regional air quality and photochemical box models, against measurements.

\section{Introduction}

The word "eclipse" derives from the ancient Greek verb $\varepsilon \kappa \lambda \varepsilon i \pi \omega$ [ikLIpo] which means to vanish. Eclipses, either solar or lunar, have been attracting the interest of people since the ancient years. Observations of solar eclipses date back to at least $2500 \mathrm{BC}$ in the writings that have survived from ancient China and Babylon. Many different cultures and civilizations (China, Babylon and Sumeria, Egypt, Greece, India, Mayas) have been predicting and recording eclipses mainly because of the pre-existing need to keep track of lunar and solar calendars, in relation with planting and harvesting of crops, health or successes of significant persons.

In modern times solar eclipses have been still triggering the attention of scientists and in cases were used for objectively testing physical hypotheses. For instance, an attempt to provide solid evidence of a theory that has changed history was related to an eclipse: in 1915 Einstein claimed in his General Theory of Relativity that massive objects warp space and time, and proposed as a test to observe light deflection from distant stars as it passes close to the sun. Four years later, another physicist, Arthur Eddington, performed

Published by Copernicus Publications on behalf of the European Geosciences Union. 
observations of stars near the sun during the total eclipse of 29 May 1919 (west coast of Africa) and soon afterwards announced that their observations supported Einstein's theory (Dyson et al., 1920).

In the current epoch the "mythical" dimension of eclipses is still alive. It is characteristic that more than one and a half million results can be found under the search "solar eclipse March 2006" in the web, indicative of people's interest in the spectacular phenomenon of the solar eclipse. Astronomers are among the scientists particularly interested in eclipses. Solar eclipses offered for many years of scientific research the only opportunity to observe and study the solar corona. Sophisticated methods were used from the ground to analyse all parts of the highly structured white-light corona. Coronal absolute intensities and line emissions, including their polarization, were also studied to analyze density and temperature inhomogeneities, velocities and magnetic fields. The space age noted a revolution in the study of the solar corona, which now is mainly supported by many orbiting solar observatories. However, eclipse observations from Earth are still of high scientific interest. The largest benefit comes from coordinating modern ground-based eclipse observations with space measurements. There are still new discoveries to be made from eclipses, by using the latest methods of investigation (very accurate timing, fast rate of measurements, wavelengths not covered from space, new experimental techniques).

Morover, solar eclipses have also been the object of special focus for various experts from different research fields. For example from the medical research field, ophthalmologists and optometrists are interested in the risk of developing solar retinopathy by simply watching a total solar eclipse (e.g. Wong et al., 2001). Psychiatric studies have investigated the impact of total solar eclipses on the incidence of suicide (e.g. Gralton and Line, 1999; Voracek et al., 2002), while from the sociological point of view the impacts of media hyper-coverage and collective anticipation of a positive event, probably by means of greater social cohesion, as well as indirect consequences, such as traffic jams and public transportation disruptions, have been also of great interest.

Finally, the response of the earth's environment to the abrupt and short-time disturbance in the radiation, and in consequence the thermal balance of the atmosphere, has been the subject of many environmental studies during the last century. The environmental effects of a solar eclipse have been mainly focused on meteorological parameters (e.g. Anderson et al., 1972), photochemistry (e.g. Srivastava et al., 1982), boundary layer physics (e.g. Antonia et al., 1979), total columnar ozone (e.g. Kawabata, 1937), gravity waves (e.g. Chimonas and Hines, 1970), ionospheric parameters (e.g. Klobuchar and Whitney, 1965) but also plants (e.g. Deen and Bruner, 1933) and animals (e.g. Zirker, 1995).

Seizing the opportunity of the total solar eclipse of 29 March 2006, visible over the eastern Mediterranean, concurrent measurements at different distances from the total ob- scuration along Greece were undertaken, with focus on the environmental impact of this phenomenon. An overview of the acquired results is presented here. Different and multidisciplinary topics related to solar eclipses are investigated, using the event as an opportunity to understand the earth's response to the abrupt decrease of solar radiation. All measurements, analyses and respective results are included in a series of component scientific papers published in the Atmospheric Chemistry and Physics Special Issue entitled "The total solar eclipse of 2006 and its effects on the environment".

\section{The March 2006 total solar eclipse}

\subsection{Description of the eclipse}

On 29 March 2006 a total solar eclipse was visible along a narrow band from Brazil to Mongolia, while a partial eclipse was seen within a much broader area along the main axis. Over the course of $3 \mathrm{~h} 12 \mathrm{~min}$, the Moon's umbra travelled for about $14500 \mathrm{~km}$, covering $0.41 \%$ of Earth's surface area. The Moon's umbral shadow first touched down on Earth in eastern Brazil at 08:36 UTC, formed a path $129 \mathrm{~km}$ wide that instantaneously reached speeds over $8000 \mathrm{~m} \mathrm{~s}^{-1}$ and travelled decelerating across the Atlantic Ocean. The shadow reached the West African coasts (Ghana) at 09:08 UTC and at that moment the path width had expanded to $184 \mathrm{~km}$ while the ground speed had decreased to $960 \mathrm{~m} \mathrm{~s}^{-1}$. It crossed north-central Africa (Togo, Benin, Nigeria, Niger, Chad, Libya and Egypt) with velocities $700-830 \mathrm{~m} \mathrm{~s}^{-1}$. Totality reached its maximum duration of $4 \min 7 \mathrm{~s}$ over Libya when the Sun's local zenith angle was $67^{\circ}$ and the path width $184 \mathrm{~km}$. The umbra turned to a northeastern course, crossed the Mediterranean coast at 10:40 UTC between Crete and Cyprus Islands, and reached the southern coast of Turkey at 10:54 UTC. It then continued towards the Black Sea, and crossed the Caucasus Mountains. As the shadow proceeded into Russia the umbral velocity increased to $1530 \mathrm{~m} \mathrm{~s}^{-1}$ and rapidly accelerated across central Asia, while the duration dwindled considerably. It finally lifted off Earth's surface at sunset along Mongolia's northern border at 11:48 UTC. More details about the path of the eclipse and various local circumstances can be found in Espenak and Anderson (2004).

\subsection{Objectives}

Emphasis was given on the response of the atmosphere to the abrupt change of the solar radiation by means of meteorological, physical and chemical parameters and on the signals found in the ionosphere and the stratosphere. However, the effect of the eclipse on marine life and crops was also an interesting aspect. This multi-disciplinary experiment enabled researchers from different scientific areas to access important parameters supplementary to their main field, thus enhancing 
their analysis and interpretation. The combined experiments were aiming to:

- Investigate the response of the earth environment to the abrupt change of the solar radiation due to the total solar eclipse.

- Study the eclipse induced effects at various distances from eclipse totality (different eclipse magnitudes) and at different air quality environments (urban, rural, semiremote etc) and synoptic conditions.

- Examine the time scale of response to the eclipse relative to the disturbance duration and whether there are natural feedbacks to the induced changes.

- Identify cases in which eclipse conditions approximate night time conditions.

- Characterise the induced disturbances as temporary or permanent with regard to return to initial state.

For these purposes several thematic areas have been investigated:

- Synoptic and Boundary Layer Meteorology

- Atmospheric Chemistry, Air Quality

- Solar radiation

- Ionosphere

- Formation and propagation of eclipse induced Gravity Waves

- Crops

- Marine life

\subsection{Experiments setup}

Scientists from several institutes and university laboratories worked together to investigate the effects of the total solar eclipse from multiple viewpoints (Table 1). The main locations where the experimental campaigns took place are depicted in Fig. 1, and detailed information concerning the main local circumstances of the eclipse at each site is provided in Table 2. The sites were located almost perpendicular to the eclipse axis from $100 \%$ to $75 \%$ eclipse magnitude, enabling the investigation of the scaled impacts of the eclipse. A brief description of the main measurement sites at Kastelorizo, Finokalia (Environmental Chemical Processes Laboratory, University of Crete, http://finokalia.chemistry. uoc.gr), Athens (National Observatory of Athens, http:// www.meteo.noa.gr) and Thessaloniki (Laboratory of Atmospheric Physics, Aristotle University of Thessaloniki, http: //lap.physics.auth.gr) is given by Founda et al. (2007).

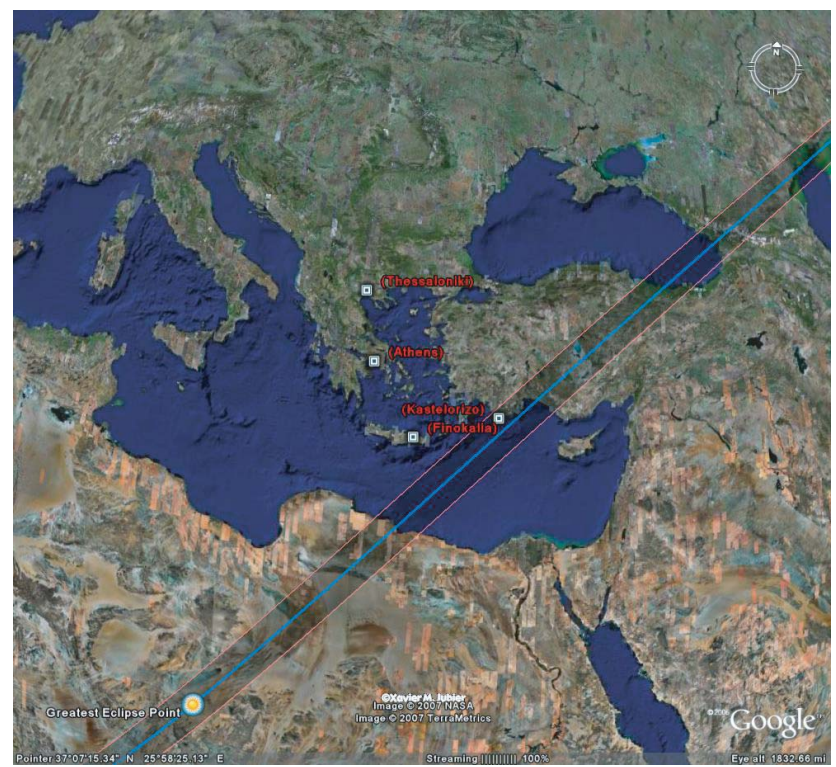

Fig. 1. The 29 March 2006 Total Solar Eclipse path over the Mediterranean area: the main stations where the measurements were conducted are denoted, and their distances from the eclipse central line are Kastelorizo $50 \mathrm{~km}$, Finokalia $240 \mathrm{~km}$, Athens $560 \mathrm{~km}$, Thessaloniki $810 \mathrm{~km}$. Both maps were produced with Interactive Google Earth with eclipse add-ons by Xavier M. Jubier (Eclipse Predictions by Fred Espenak, NASA's GSFC).

From 28 to 30 March 2006, meteorological, air quality and actinometric parameters were continuously monitored at all stations, as described in the accompanying eclipse Special Issue papers. Total column ozone and solar spectral irradiance measurements were conducted at Kastelorizo, Athens and Thessaloniki with Brewer spectroradiometers (Kazadzis et al., 2007). In addition, measurements from the NILUUV multi-filter radiometers of the Greek UV Network were also used for the investigation of the eclipse effects (http: //www.uvnet.gr; Kazantzidis et al., 2007).

Three additional experimental setups were deployed for this study: An oceanographic cruise on board the R/V AEGAIO of the Hellenic Center for Marine Research (HCMR) was carried out on 29 March 2006, at a fixed station close to Kastelorizo Island in the Eastern Mediterranean (Economou et al., 2007). The effects of the solar eclipse on crops were investigated in the experimental field of the Agricultural University of Athens, at an altitude of $30 \mathrm{~m}$ above sea level (Economou et al., 2007).

Finally, the ionospheric response to the solar eclipse of 29 March 2006 over Athens was studied by using ionospheric observations collected via a standard vertical incidence ionospheric sounding campaign. This was conducted at National Observatory of Athens (P. Penteli: $38^{\circ} 00 \mathrm{~N}, 23^{\circ} 30 \mathrm{E}$ ) by using a DPS-4 (Digisonde Portable Sounder - 4) ionosonde. During the campaign period (from 27 to 31 March 2006), the time resolution of the soundings was adjusted for the 
Table 1. Main Research Institutes and University Laboratories that have actively participated in the experimental campaigns in Greece during the 29 March 2006 Total Solar Eclipse.

\begin{tabular}{llll}
\hline & Participant & Legal Entity & Abbrv \\
\hline 1 & Institute for Environmental Research and Sustainable Development & National Observatory of Athens & IERSD-NOA \\
2 & Institute for Space Applications and Remote Sensing & National Observatory of Athens & ISARS-NOA \\
3 & Institute of Astronomy and Astrophysics & National Observatory of Athens & IAA-NOA \\
4 & School of Applied Mathematical and Physical Sciences, Physics Div. & National Technical Univ. of Athens & NTUA \\
5 & Laboratory of Agronomy, Faculty of Plant Production & Agricultural University of Athens & AUA \\
6 & Institute of Oceanography & Hellenic Center for Marine Research & HCMR \\
7 & Laboratory of Atmospheric Physics, Physics Dept. & Aristotle University of Thessaloniki & LAP-AUTH \\
8 & Environmental and Chemical Processes Laboratory, Chemistry Dept. & University of Crete & ECPL-UOC \\
9 & Division of Biomedical Physics & Innsbruck Medical University, Austria UI & University of Manchester, UK
\end{tabular}

Table 2. Stations' coordinates and basic eclipse related information. Abbreviations and explanation of special terms: C1 - 1st contact, C2 2nd contact, Mid - maximum phase of the eclipse or mid eclipse, C3 - 3rd contact, C4 - 4th contact, Magnitude - the fraction of the sun's diameter covered by the moon at mid eclipse, Moon/sun size ratio - ratio of the apparent size of the moon to that of the sun, Alt - altitude of the sun, Azi - azimuth of the sun, P - angle between the north point of the sun's disk and the contact point with the moon, V - the o'clock position on the sun's face of the contact point with the moon. Data for this table were retrieved from Interactive Google Map from Xavier M. Jubier using Eclipse Predictions by Fred Espenak, NASA's GSFC (see acknowledgements).

\begin{tabular}{|c|c|c|c|c|c|c|c|c|c|c|c|c|}
\hline \multirow[b]{2}{*}{ Location } & \multirow[b]{2}{*}{ Lat } & \multirow[b]{2}{*}{ Long } & \multicolumn{3}{|c|}{ Eclipse Circumstances (UTC) } & \multicolumn{3}{|c|}{ Eclipse information } & \multicolumn{4}{|c|}{ Solar parameters (mid eclipse) } \\
\hline & & & $\mathrm{C} 1$ & Mid & $\mathrm{C} 4$ & Coverage & Magnitude & Moon/Sun & Alt & Azi & $P$ & $\mathrm{~V}$ \\
\hline & & & $(\mathrm{C} 2)$ & & (C3) & $\%$ & mid eclipse & size ratio & & & & \\
\hline Kastelorizo & $36^{\circ} 09^{\prime}$ & $29^{\circ} 35^{\prime}$ & $\begin{array}{l}9: 34: 44 \\
(10: 51: 58)\end{array}$ & $10: 53: 27$ & $\begin{array}{l}12: 10: 46 \\
(10: 53: 26)\end{array}$ & 100 & 1.00934 & 1.04952 & $56^{\circ}$ & $201^{\circ}$ & $137^{\circ}$ & 8 \\
\hline Finokalia & $35^{\circ} 20^{\prime}$ & $25^{\circ} 40^{\prime}$ & $9: 27: 48$ & $10: 46: 25$ & $12: 04: 33$ & 95.6 & 0.95655 & 1.04991 & $58^{\circ}$ & $191^{\circ}$ & $137^{\circ}$ & 7.8 \\
\hline Athens & $38^{\circ} 03^{\prime}$ & $23^{\circ} 52^{\prime}$ & $9: 30: 33$ & $10: 47: 19$ & $12: 03: 46$ & 84 & 0.86476 & 1.04946 & $55^{\circ}$ & $188^{\circ}$ & $137^{\circ}$ & 7.6 \\
\hline Thessaloniki & $40^{\circ} 38^{\prime}$ & $22^{\circ} 57^{\prime}$ & $9: 34: 25$ & 10:49:10 & 12:03:39 & 75.1 & 0.79435 & 1.04897 & $53^{\circ}$ & $187^{\circ}$ & $138^{\circ}$ & 7.6 \\
\hline
\end{tabular}

needs of the eclipse event to $4 \mathrm{~min}$ from 08:00 UTC to 15:00 UTC and $15 \mathrm{~min}$ for the rest of the day. The corresponding ionograms' traces were scaled manually and the true height plasma frequency profiles up to the F2 layer peak density height were calculated using the ionogram inversion technique described by Huang and Reinisch (1996). From the bottomside profiles the lowest frequency reflected from the ionosphere and recorded in the ionogram, fmin, the critical frequencies foE, foF1 and foF2 providing the maximum frequency which can be reflected from each ionospheric layer as well as the F2 layer peak density height, hmF2 were obtained. The electron density profiles were also extrapolated to the topside ionosphere up to $1000 \mathrm{~km}$ based on the Huang and Reinisch (2001) model. This made possible the estimation of the ionosonde total electron content (ITEC) of the ionosphere, providing the electron content up to $1000 \mathrm{~km}$ (Belehaki and Kersley, 2006; Belehaki et al., 2003). The profiles were calculated with an altitude step of $10 \mathrm{~km}$ and from them the time series of the electron density at fixed ionospheric altitude zones was extracted.

\subsection{Synoptic meteorological situation}

The general synoptic pattern did not change considerably during the period of study (28-30 March 2006). A pronounced low pressure system prevailed over Central-North Europe and high pressures occurred to the South, over North Africa (NOAA, http://www.arl.noaa.gov/ready.html).

On the pre-eclipse day (28 March, 12:00 UTC) a depression centred over the north of Italy, with an accompanying cold front extending down to the north coast of Africa, moved eastwards (not shown). The day was bright and sunny over the Southern Aegean Sea. An average cloudiness of 3 okta was observed over Athens greater area, mainly due to cirrus ( $\mathrm{Ci}$ ) and altocumulus (Ac), which gradually increased to 8 okta by the end of the day with the parallel formation of cirrostratus (Cs). The initial cloud coverage of 2 okta over North Greece increased to 5 okta by the evening consisting of low and high clouds.

On 29 March (06:00 UTC) a secondary low pressure system developed over the Balkans with an associated trough 


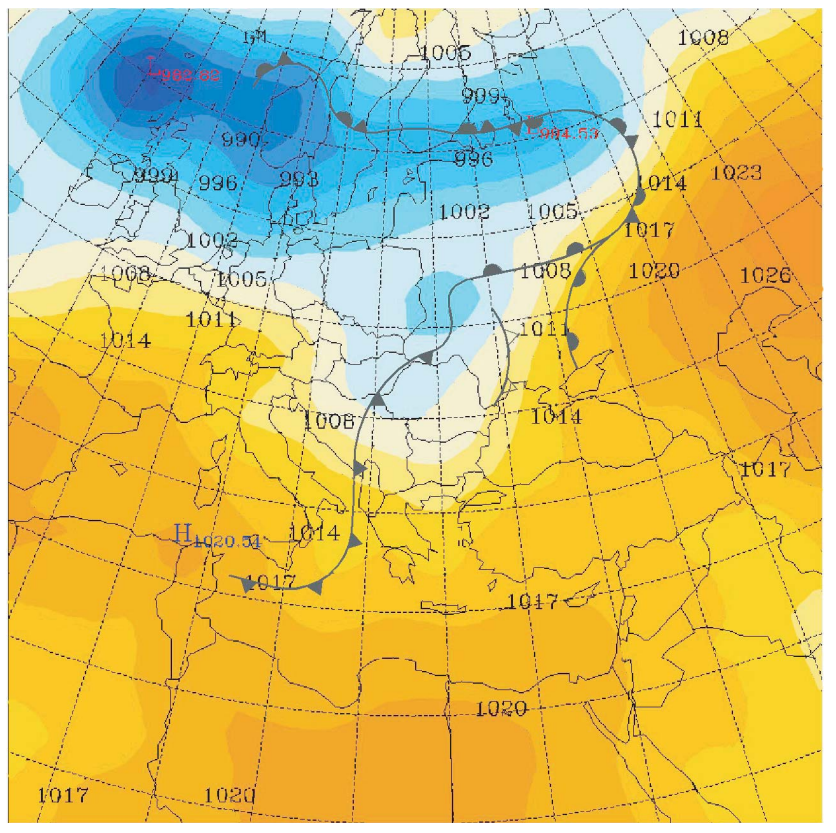

Fig. 2. NOAA surface pressure map (contour labels in $\mathrm{hPa}$ ) on 29 March 2006, 06:00 UTC (http://www.arl.noaa.gov/ready.html). Frontal analysis from UK MetOffice at the same time has been superimposed on the map (http://www.metoffice.gov.uk).

extending over central Greece. At that time the cold front began approaching the NW parts of Greece (Fig. 2). At the south stations (Kastelorizo, Finokalia) the sky was clear and only a few hours before the eclipse thin $\mathrm{Ci}$ first developed followed by sparse $\mathrm{Cu}$ and $\mathrm{Ac}$ formation (Fig. 3). This cloud structure prevailed during the eclipse occasionally obscuring the solar disk, until 25 min before the fourth contact when more Ac developed. An 8 okta cloud cover was observed over Athens, consisting of $\mathrm{Ci}$ and $\mathrm{Cs}$, but the solar disk was visible through lighter clouds. At Thessaloniki, almost clear sky conditions (with sparse $\mathrm{Cu}$ ) prevailed in the morning of the eclipse day, however, the solar disc was obscured by low clouds about one hour after the first contact (see also Amiridis et al., 2007).

Near the fourth contact (12:00 UTC) the trough propagated further to the south and the surface pressure continued to decrease at all stations (not shown). The lower edge of the broken cold front has now moved to the south and crosses the west side of central Greece. Cs and Ac (6 okta) were reported over Athens during the eclipse, and a few hours later, cloud coverage decreased to 4 okta with $\mathrm{Ci}$ dominating. In the afternoon (18:00 UTC) the trough moved to the East and pressure increased again. Cloud coverage was 4 okta over Athens (mainly $\mathrm{Ci}$ ), while 2 okta low clouds and 6 okta high clouds were reported over the southeastern Aegean. On the next day (30 March) cloudy conditions prevailed over central and south Greece whereas clearer sky was observed to the North.

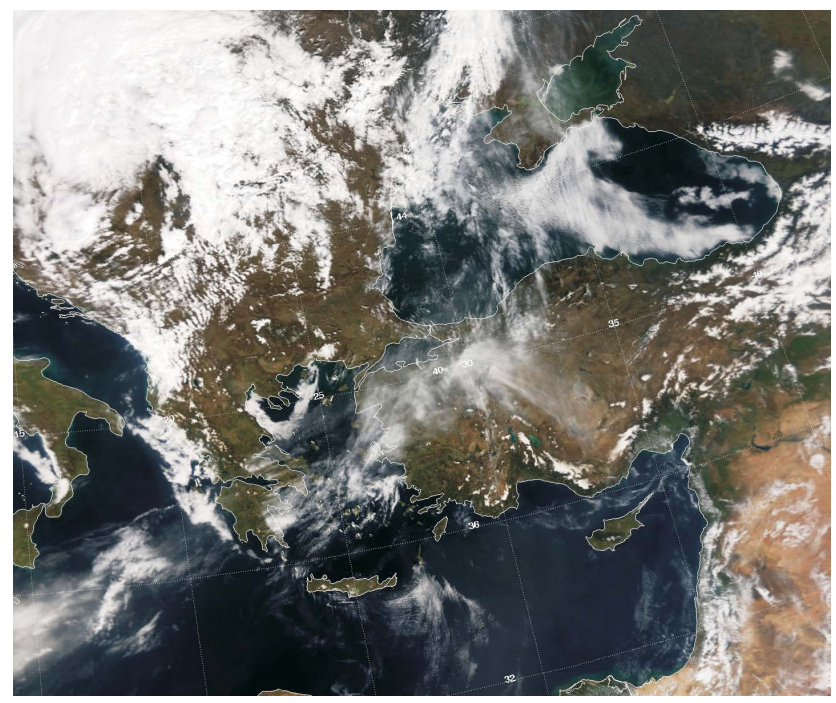

Fig. 3. MODIS-Terra image acquired on 29 March 2006 (09:00 UTC). Image is a composite of visible channels (0.469, 0.555 and $0.645 \mu \mathrm{m}$ for the blue green and red colors).

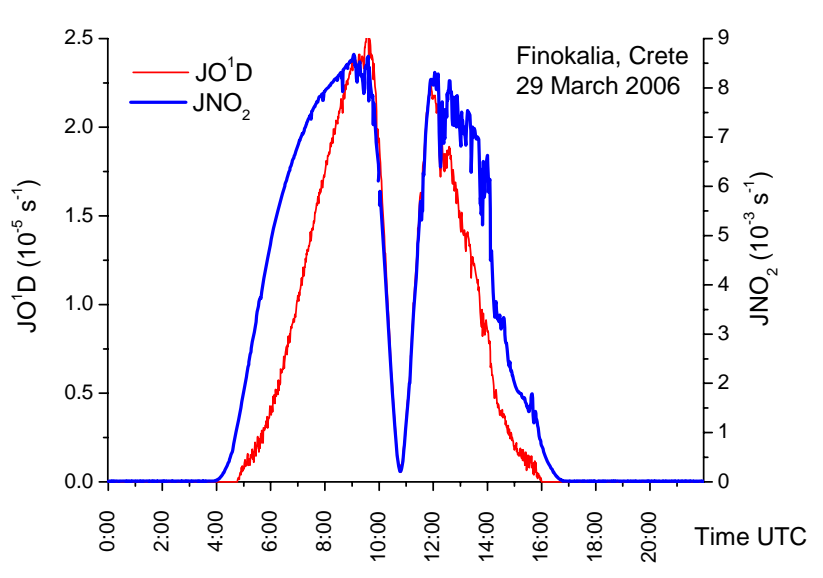

Fig. 4. Photolysis rates of $\mathrm{O}_{3}$ and $\mathrm{NO}_{2}, \mathrm{JO}^{1} \mathrm{D}$ and $\mathrm{JNO}_{2}$, respectively, at Finokalia station, Crete Island, on 29 March 2006.

\section{The effects of the solar eclipse on various atmospheric layers and the biosphere}

\subsection{Troposphere}

\subsubsection{Meteorology}

A solar eclipse constitutes a challenge for the study of the lower atmosphere response to the abrupt change of the incident solar radiation. Temperature, relative humidity, wind and cloudiness are among the most common meteorological parameters measured and observed in experimental campaigns during solar eclipses (e.g. Anderson, 1999; Fernandez et al., 1993, 1996; Aplin and Harrison, 2002). Although the results of most meteorological studies provide similar 
patterns of temperature changes, the precise drop may differ depending on several factors (timing, synoptic situation, surrounding environment, percentage of sun occultation etc). The influence of solar eclipses on cloudiness has been reported by several observers mainly as a characteristic formation of "eclipse clouds" or dissipation of the existing convective cloudiness (e.g. Hanna, 2000). An "eclipse wind" has been also reported during many eclipses (e.g. Aplin and Harrison, 2002), although in some cases it could be also related to subjective perception of a pronounced wind chill effect (Anderson, 1999). According to recent observations (e.g. Fernandez 1993, 1996; Eaton et al., 1997) mean wind speed (and/or its turbulent component) decreases, however, on a local scale orographic winds can form and sea-land circulations can be enhanced.

The meteorological observations at different sites within Greece during the 29 March 2006 total solar eclipse, showed that all studied variables were affected by the eclipse, due to the dramatic reduction in the incoming shortwave solar radiation, depending on the eclipse magnitude and local cloudiness (Founda et al., 2007).

In particular, the surface air temperature decrease (in average $2 \mathrm{~m}$ a.g.l., see Founda et al., 2007 for details) was about $2.3^{\circ} \mathrm{C}$ at the southern stations and $2.7^{\circ} \mathrm{C}$ and $3.9^{\circ} \mathrm{C}$ at the central and northern stations, respectively, indicating that the temperature drop was not determined by the eclipse magnitude, but by the surrounding environment and the local conditions. For instance, the coastal southern stations experienced a lower surface temperature drop, due to the influence of the sea, which limited the effect of the eclipse. At Thessaloniki, the formation of thick cloudiness during the eclipse accounted for the pronounced surface temperature drop at this site. On average the lowest temperatures occurred about 15 minutes after the maximum eclipse phase.

At Thessaloniki soil temperature at depths 10 and $20 \mathrm{~cm}$ were also available. The normal diurnal course of soil temperature at both depths slowed down for the period between mid-eclipse and the fourth contact, after which it resumed its normal march.

A surface wind speed decrease of the order of $2 \mathrm{~m} \mathrm{~s}^{-1}$ not accompanied by any simultaneous change in wind direction - was observed at most sites during the eclipse. This decrease was related to the cooling and stabilization of the atmospheric boundary layer as detected by lidar measurements (Amiridis et al., 2007). At Kastelorizo, the effect of the eclipse on wind appeared as a decrease in the turbulent wind component (gustiness), for a short period near eclipse totality.

The eclipse effect on meteorological variables was simulated using the Weather Research and Forecast (WRF) numerical model (Founda et al., 2007). This has been a real challenge due to the complexity of the domain comprising of continental and extended water covered parts. The simulated reduction of the incoming solar irradiance was proportional to the eclipse magnitude and in good agreement with obser- vations. Strong anomalies of the simulated air surface temperature (at $2 \mathrm{~m}$ a.g.l.) were more pronounced near the time of the observed surface temperature minimum. The simulated surface temperature anomalies were in excellent agreement with observations at the central and southern stations. The effect of the eclipse on simulated surface temperature at the southern stations (islands) minimized due to the influence of the sea. Finally WRF did not simulate any significant impact of the eclipse on the horizontal wind field.

\subsubsection{Boundary layer}

As already discussed in Sect. 3.1.1 one of the most dramatic meteorological impacts of a solar eclipse is the change in surface temperature. A change in the radiative heating or cooling of the atmosphere is felt first in the Atmospheric Surface Layer (ASL) where turbulence processes dominate in the mass, energy and momentum transport. Not much effort has been devoted up to now to the study of turbulence and spectral characteristics of the ASL and by extension the Planetary Boundary Layer (PBL) during solar eclipses. However, in the few studies investigating PBL changes during solar eclipses, important findings are reported. Antonia et al. (1979), Segal et al. (1996) and Eaton et al. (1997) showed that a solar eclipse affects the sensible heat-flux and the radiation flux near the surface and that the surface layer turbulence approximately follows a continuum of equilibrium states in response to the stability changes brought about by the change in surface heat flux. During the solar eclipse of 11 August 1999, Kolev et al. (2005) also demonstrated that the solar eclipse affects the meteorological parameters of the atmosphere near the ground, the ozone concentration and the height of the mixing layer.

During the solar eclipse of 29 March 2006, PBL height evolution over Greece, was investigated (Amiridis et al., 2007), using lidars and ground meteorological instruments. They reported on a solar eclipse induced decrease of the PBL height, indicating a suppression of turbulence activity similar to that during sunset hours. In particular, changes in PBL height were associated with a very shallow entrainment zone, indicating a significant weakening of the penetrative convection. The heat transfer was confined to a thinner layer above ground and the thickness of the entrainment zone exhibited its minimum during eclipse totalilty, demonstrative of turbulence suppression at that time. Model estimations of the PBL evolution were additionally conducted using the Comprehensive Air Quality Model with extensions (CAMx) coupled with the Weather Research and Forecasting model (WRF). Model diagnosed PBL height decreased during the solar eclipse due to vertical transport decay, in agreement with the experimental findings, while vertical profiles of atmospheric particles and gaseous species showed an important vertical mixing attenuation. 


\subsubsection{Photochemistry}

The area under study is characterized by particularly enhanced level of pollutants by means of ozone (Kourtidis et al., 2002; Kouvarakis et al., 2002; Kondratyev and Varotsos, 2002; Gerasopoulos et al., 2005; 2006a) and particulate matter (Gerasopoulos et al., 2003, 2006b) that also influence the fraction of solar irradiance reaching the surface (Zerefos et al., 1998; Papayannis et al., 1998; Varotsos et al., 2001). Total solar eclipses enable the evaluation of our understanding of air pollution build-up and of the response of the gas-phase chemistry of photo-oxidants during a drastic perturbation in solar radiation. The impact of the total solar eclipse on tropospheric chemistry has been investigated in only a few previous studies (e.g. Abram et al., 2000; Zanis et al., 2001).

Zanis et al. (2007) present the chemical effects of the solar eclipse of 29 March 2006 on surface ozone and other photo-oxidants at four sites in Greece, Kastelorizo, Finokalia (Crete), Pallini (Athens) and Thessaloniki, which are located at gradually increasing distances from the eclipse path and are characterized by different air pollution levels. In addition to in situ observations, a photochemical box model and a 3-D regional air-quality model have been deployed for the simulation of the eclipse effects on photochemistry.

At the relatively unpolluted sites of Kastelorizo and Finokalia, no clear impact of solar eclipse on surface $\mathrm{O}_{3}, \mathrm{NO}_{2}$ and NO concentrations has been deduced from the observations. According to Zanis et al. (2007) these changes were rather small compared to the variability of the chemical species and hence the solar eclipse effects could be easily masked by transport. At the polluted urban and suburban sites of Thessaloniki and Pallini, respectively, solar eclipse effects on $\mathrm{O}_{3}, \mathrm{NO}_{2}$ and $\mathrm{NO}$ concentrations were clearly indicated from both measurements and 3-D air-quality modeling. The net effect averaged over the time window of the eclipse (09:30-12:00 UTC) was a decrease in $\mathrm{O}_{3}$ (by about 4-6 ppbv) and $\mathrm{NO}$ (1-2 ppbv) while $\mathrm{NO}_{2}$ was accumulated (by 3-4 ppbv) in absence of photo-dissociation..

Overall, it was evident from the 3-D air quality modeling over Greece that the maximum effects of the eclipse on $\mathrm{O}_{3}$, $\mathrm{NO}_{2}$ and $\mathrm{NO}$ occurred at the large urban agglomerations of Athens, and Thessaloniki where the peak of emissions takes place. The common behaviour of $\mathrm{O}_{3}, \mathrm{NO}_{2}$ and $\mathrm{NO}$ concentrations at the two polluted sites, Pallini and Thessaloniki, was attributed to their perturbation from the photostationary state during the eclipse, with $\mathrm{NO}_{2}$ formed from the reaction of $\mathrm{O}_{3}$ with $\mathrm{NO}$ and not being efficiently photolysed.

Driven by the variations of the observed photolysis rates of $\mathrm{NO}_{2}\left(\mathrm{JNO}_{2}\right)$ and ozone $\left(\mathrm{JO}^{1} \mathrm{D}\right)$ during the eclipse period, the box model simulated a sharp change from daytime to nighttime chemistry (Zanis et al., 2007). During the eclipse period hydroxyl $(\mathrm{OH})$ and hydrogen peroxy $\left(\mathrm{HO}_{2}\right)$ radicals, mainly photochemically produced, showed rapid decrease by more than an order of magnitude to nighttime levels. Simultaneously the nitrate $\left(\mathrm{NO}_{3}\right)$ radical - mainly present at night - in- creased to the pptv level typical of nighttime conditions over the area (Vrekoussis et al., 2006, 2007). This drastic and sudden change from daytime to nighttime chemistry during the eclipse has also markedly affected the modelled $\mathrm{O}_{3}$ budget changes simulated by the chemical box model. Indeed, a decrease in the net ozone production rate of the order of $1 \mathrm{ppbv} / \mathrm{h}$ was calculated when integrated over the eclipse period, with much higher rates around the maximum eclipse magnitude.

Another study focusing on the effects of this solar eclipse on urban levels of pollution, in conjunction with meteorological and actinometric parameters, is given by Tzanis et al. (2007). They report that surface ozone concentration decreased after the eclipse event for almost two hours and the maximum percentage change was observed one hour after the maximum of the solar eclipse at all stations. The greater values of surface ozone percentage change were observed at the station located in the center of Athens.

\subsubsection{Radiation}

Several measurements of solar radiation during total eclipses have been carried out, mainly in the 1960s and 1970s but also recently (e.g. Sharp et al., 1971; Silverman and Mullen, 1975, Zerefos et al., 2000 and 2001). Their main focus has been the study of eclipse-induced changes in the spectral solar irradiance at the earth's surface, the effects of multiple scattering on sky brightness and the wavelength dependence of the limb darkening effect, as well as to test radiative transfer models.

The dramatic reduction of the incoming solar radiation observed at all sites just after the first contact, proportional to the eclipse magnitude, is presented by Founda et al. (2007). In particular, the reduction of global solar radiation ranged between $89 \%$ at Thessaloniki (75\% eclipse magnitude) and $100 \%$ at Kastelorizo (100\% eclipse magnitude).

A special two-day actinometric campaign was organized at Kastelorizo with spectral solar measurements of global, direct irradiance and actinic fluxes (Kazadzis et al., 2007). The spectral effect of the limb darkening to the solar radiation reaching the ground was thoroughly investigated. The results revealed wavelength dependent changes in the measured solar spectra as the eclipse magnitude increased. A much more pronounced decrease in the radiation at the shorter wavelengths was observed, compared to the longer wavelenghts. RTM System for Transfer of Atmospheric Radiation (STAR) calculations of the extraterrestrial (ET) solar flux spectrum (Köpke et al., 2001) was additionally used. The comparison of model results and measurements showed that previous model calculations have underestimated the spectral limb darkening effect, especially close to the totality of the solar eclipse. Calculations of the ET solar spectrum and the sun's effective temperature revealed an artificial change in both quantities. This is due the fact that during the eclipse the ET can not be described by the Planck function, as it is a 


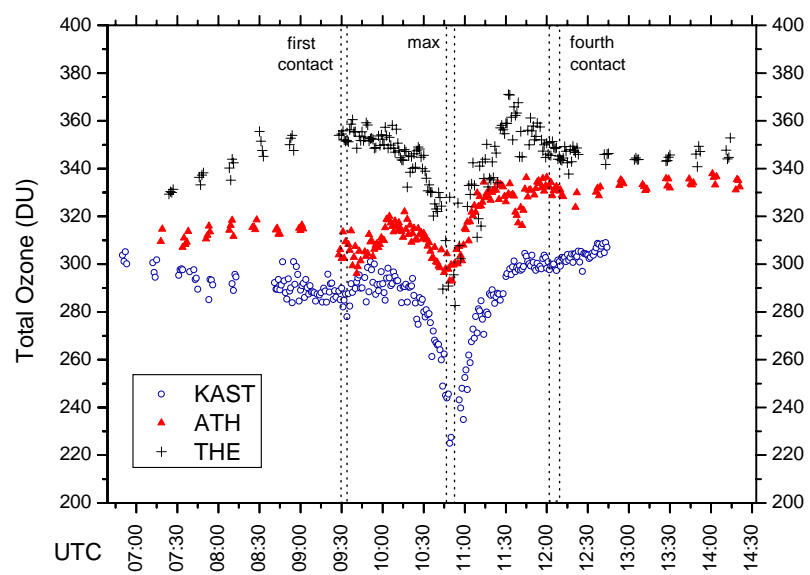

Fig. 5. Total Ozone Column on 29 March 2006 over Greece, at Kastelorizo (KAST), Athens (ATH) and Thessaloniki (THE) using Brewer spectroradiometers. Dotted lines represent the time windows of the first contact, the mid eclipse and the fourth contact at the different sites (see Table 2 for detailed eclipse circumstances).

mixture of black body radiation originating from parts of the solar disc with different effective temperatures.

Kazantzidis et al. (2007) use measurements from the Greek UV monitoring network to investigate the variability of the ultraviolet and the photosynthetically active radiation (PAR) during the total solar eclipse. They showed that although the radiation at shorter wavelengths are generally influenced more by the eclipse, at large eclipse percentages $(>85 \%)$ the behaviour is inverse, and radiation at shortest wavelength $(305 \mathrm{~nm})$ decreases slower as the eclipse approaches its maximum, compared to that at the longer wavelengths. The comparison of the measured changes in UV and visible irradiance with 1-D model calculations (accounting for the limb darkening effect) showed differences up to $30 \%$ for the shorter UV wavelengths, at high eclipse percentages. Measured surface UV irradiance during the eclipse totality was compared for the first time with 3-D radiative transfer model calculations showing very good performance of the model.

Emde and Mayer (2007), for the first time describing the eclipse phenomenon, used a 3-D radiative transfer model to perform backward Monte Carlo calculations. They computed the diffuse radiation in the umbra and simulated the changing colours of the sky. Taking into account multiple scattering, they have produced accurate results below the umbra, where 1-D approximations used in previous studies have completely failed. The total solar eclipse has been an ideal situation to test the accuracy of the code and improve the parameterization of cloud properties. The obtained results contribute in planning and optimising future radiation experiments.
Psiloglou and Kambezidis (2007) used the Meteorological Radiation Model (MRM), developed by the Atmospheric Research Team of the National Observatory of Athens, to reproduce the observed solar irradiance and evaluate the performance of the latest version 5 of the MRM algorithm. Cloudiness during an eclipse event is simulated for the first time, in the international literature, with a solar broadband model. MRM v5 is shown to be an efficient broadband code capable in simulating solar irradiance during the solar eclipse of 29 March 2006 over Athens and under cloudy conditions.

\subsection{Stratosphere}

\subsubsection{Total ozone}

Several earlier and more recent studies have examined the possible influence of solar eclipses on the total column ozone (e.g. Kawabata, 1937; Stranz, 1961; Chakrabarty et al., 1997; Zerefos et al., 2000). Dobson spectrophotometric observations show an increase of total ozone near the maximum eclipse occultation (e.g. Bojkov, 1968; and references therein), while other studies using different instruments report on a varying sign and magnitude of total ozone changes linked to an eclipse (e.g. Mims and Mims, 1993; Chakrabarty et al., 1997). Zerefos et al. (2000) pointed out that total ozone reductions of more than $30 \mathrm{DU}$ can be artificially introduced in routine total ozone measurements with Brewer spectrophotometers. They attributed this to the diffuse light increases by more than $30 \%$ with respect to the direct solar radiation, mainly towards shorter UV wavelengths.

During the experiments of the 29 March 2006 total solar eclipse, the total column of ozone was measured using Brewer spectrophotometers at Kastelorizo, Athens and Thessaloniki (Fig. 5). In general, total ozone was about 30-40 DU lower on the day of the eclipse than the day before. A trend of increasing total ozone with the distance from the eclipse axis has been observer and can be attributed to the synoptic situation encountered over central Europe. Indeed, the 29 March Total Ozone Map as retrieved from SCIAMACHY observations (Fig. 6; WMO Northern Hemisphere Ozone Mapping Center, http://lap.phys.auth.gr/ozonemaps/), indicates a tongue of high total ozone values over central Europe, linked to the dominating low pressure system discussed in Sect. 2.4.

During the course of the eclipse, a gradual drop in total ozone followed by a symmetric to the drop increase after totality is seen. This characteristic artificial decrease of total ozone during a solar eclipse, also observed in the past (e.g. Zerefos et al., 2000), was evidenced at all sites. In particular, at Kastelorizo a drop of 50 DU was encountered corresponding to a decrease of $\sim 17 \%$, while at Athens and Thessaloniki the corresponding decreases were $25 \mathrm{DU}$ $(\sim 8 \%)$ and 57 DU $(\sim 16 \%)$, respectively. Radiative transfer model calculations quantified the contribution of the limb darkening effect to this eclipse induced decrease, which was far too small to explain the large decrease in total ozone 
column, derived from the standard Brewer measurements (Kazadzis et al., 2007). It is suggested that this decrease in total ozone is an artifact in the measured irradiance due to the increasing contribution of diffuse radiation against the decreasing direct irradiance caused by the eclipse. Remote sensing, direct sun techniques for ozone calculations fail to provide accurate retrievals in radiation fields when the diffuse component is dominant, such as after a certain eclipse phase.

Temporal variations of the total column ozone during the eclipse, as registerd by the Greek UV network, did not reveal any consistent trend in total ozone column (Kazantzidis et al., 2007). At four stations, total ozone showed an increase of 5-24 DU between the initial and final phases of the eclipse, at one station total ozone slightly decreased and at three stations no significant changes were observed. Since the irradiance at eclipse percentages $>85 \%$ decreased with slower rates than for longer wavelengths, the total ozone derived from the $305 / 320 \mathrm{~nm}$ ratio, showed also an artificial reduction for high eclipse percentages.

\subsubsection{Gravity waves in the stratosphere}

Chimonas (1970) hypothesized that during a solar eclipse the disturbance of the heat balance (cooling) along the supersonic travel of the trajectory of the moon's shadow could generate gravity waves (GWs). This has triggered numerous model and experimental attempts to test the hypothesis and derive the main characteristics of the waves. Earlier studies have reported observational evidence on the formation and propagation of eclipse induced gravity waves at different atmospheric heights (e.g. Jones, 1999; Seykora et al. 1985; Singh et al., 1989; Hanuise et al., 1982). However, observational evidence of the characteristic bow-wave response of the atmosphere to eclipse passages still remains equivocal (Eckermann et al., 2007).

Zerefos et al. (2007) performed concurrent measurements at three layers in the atmosphere namely the troposphere, the stratosphere and the ionosphere, and provided for the first time combined experimental evidence that the eclipse induced cooling of the ozone layer in the stratosphere is the main source of gravity waves propagating both upwards and downwards. In particular, they used Spectral Fourier Analysis on total ozone column and found a dominant oscillation in the range of 30-40 min at various distances from the eclipse totality. Their finding was additionally endorsed by $\mathrm{JO}_{1} \mathrm{D}$ and UV irradiance ( $305 \mathrm{~nm}$ ) measurements, both sensitive to columnar ozone variability, which also revealed similar oscillations at the same periodicity range. The discussed range of periodicities could not be identified on the previous or on the following day from the eclipse, strengthening their linkage to eclipse induced effects and in particular the formation of GWs.

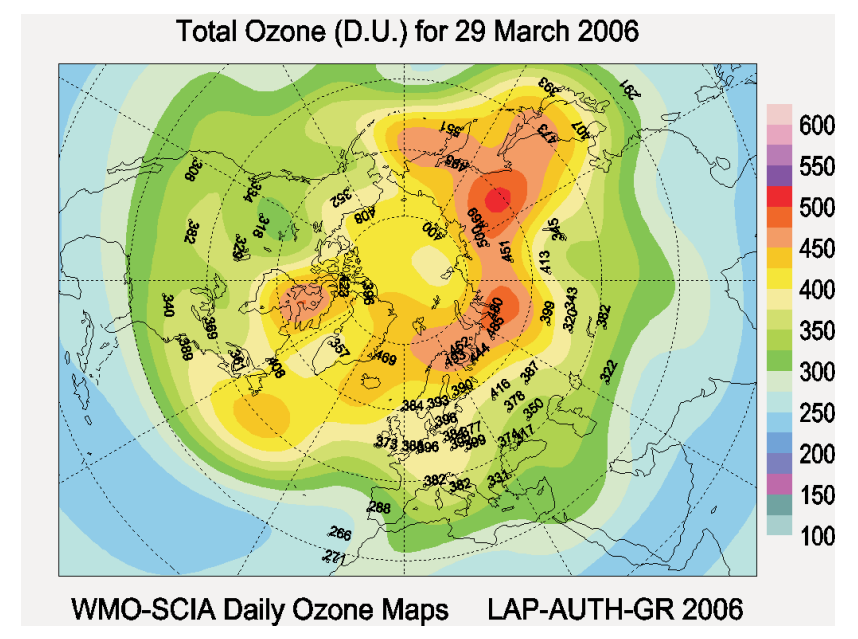

Fig. 6. The 29 March 2006 total ozone map from the SCIAMACHY satellite available from WMO Northern Hemisphere Ozone Mapping Center (http://lap.physics.auth.gr/ozonemaps/). Total Ozone color scale and values over sites are given in Dobson Units (D.U.).

The GWs formed in the stratosphere propagated into both the ionosphere (Sect. 3.3.2) and the troposphere. In the troposphere, records of surface temperature and relative humidity have revealed distinct oscillations within the same period range as in the stratosphere. However, Zerefos et al. (2007) state that no firm conclusions on the influence of GWs induced by the eclipse on the troposphere can be deduced, due to the modest amplitude of these waves and the manifold rationale inside the boundary layer.

\subsection{Ionosphere}

\subsubsection{Ionospheric response}

A solar eclipse is a unique opportunity to study the transitory changes of the ionosphere caused by decreasing and increasing the solar ionizing radiation (Altadill et al., 2001). From the earliest days of ionospheric research, great interest has been taken in the effects of solar eclipses. This is shown by the bibliography, "Literature on Solar Eclipses and the Ionosphere", containing about 200 items dated from 1912 to 1955, which is appended to the book Solar Eclipses and the Ionosphere (Beynon and Brown, 1956). Since then there have been many developments supported by both theoretical and experimental results, but because solar eclipses are rare events, the regular ionospheric effects of solar eclipses are still not completely understood.

During a solar eclipse, within a much shorter range of time than the usual day-night period, the ionosphere reconfigures itself into a state similar to that of a night-time situation, the photochemical activity decreases almost to night-time levels and then increases back to daytime values. The solar flux first rapidly decreases, causing a cooling of the atmosphere at 

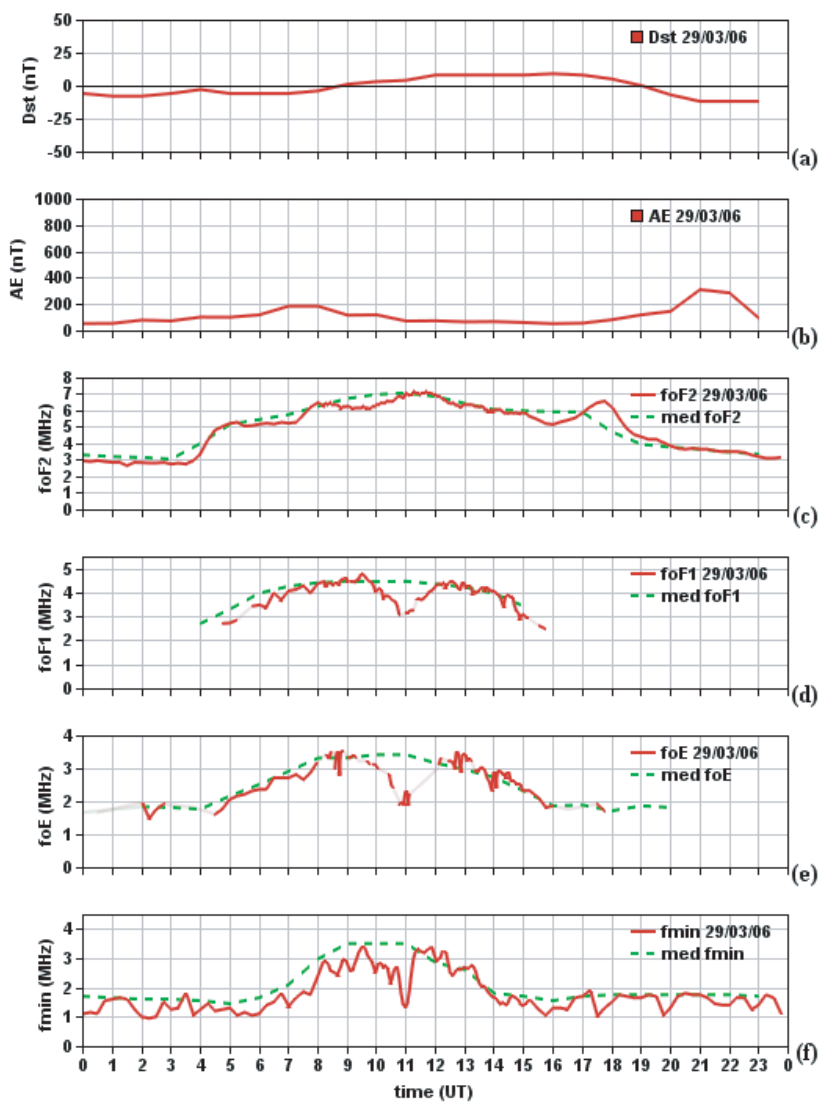

Fig. 7. Hourly values of the Dst and AE indices for the eclipse day 29 March 2006 (a and b respectively). Next are presented the variations of the critical frequencies foE, foF1 and foF 2 and the parameter fmin, marked with the red solid line. The ionospheric reference level is given by the 30-days median value centered at the eclipse day, noted with green colour.

all heights and cessation of the ionization processes at ionospheric heights, then it increases yielding heating and return to a standard day state. Solar eclipses also induce dynamical disturbances in the neutral atmosphere and ionosphere that result in changes in the reflection heights, in the electron concentration at all ionospheric heights, and in the total electron content of the ionosphere which could be identified as typical of a night-time ionosphere. However, the movement of the eclipsed region at supersonic speed clearly differs from that of regular solar terminators at sunrise and sunset times (Sauli et al., 2006). The ionospheric effect of a solar eclipse depends on various factors, such as geophysical conditions, latitude, longitude and local time (Baran et al., 2003). From this point of view, one can argue that the ionospheric measurements during solar eclipses are rare and exceptional natural experiments that enable the study and understanding of dynamical processes, mechanisms and wave propagations at work in the ionosphere.
To fair evaluate ionospheric findings during a solar eclipse event one has first to check the corresponding geophysical conditions. For this purpose, hourly values of Dst index, as indicator of the geomagnetic activity level and of $\mathrm{AE}$ index as indicator of the auroral electrojets' intensity were used in our analysis. According to the observations (Fig. 7a and b), this solar eclipse took place under low geomagnetic and magnetospheric activity, since the Dst index values ranged above $-30 \mathrm{nT}$ during the whole day and AE index never exceed the $500 \mathrm{nT}$ (Mayaud, 1980). Therefore, the impact of the solar eclipse on the ionosphere was not unduly complicated by geomagnetic or magnetospheric disturbances and this provides us with clear advantages for the identification of solar eclipse induced effects in the ionosphere. The variations of the parameter fmin and the critical frequencies foE, foF1 and foF2 are shown in Fig. 7f, e, d, and c, respectively (red solid line). The ionospheric reference level is given by the 30-day median value centered at the eclipse day, noted with green color. The decrease in the ionization in most ionospheric layers (D, E, F1) is obvious, although each differs in magnitude. The parameter fmin is a measure of the Dregion ionization (Chandra et al., 1997). During the eclipse day fmin values dropped below $1.5 \mathrm{MHz}$, corresponding to a decrease of about $62 \%$ in respect to the normal daytime values. Note that the $\mathrm{D}$ layer of the ionosphere is the most sensitive to the loss of sunlight, because it is the lowermost of the layers and is quickly overwhelmed by the neutral air around it, once the active source ionizing radiation from the sun is removed. At the same time, the critical frequency of the E layer, foE shows a significant decrease of about $44 \%$ in respect to its normal daytime values and the corresponding decrease in foF 1 is about $32 \%$, as a result of the stronger solar dependence of the $\mathrm{E}$ layer and the lower part of the $\mathrm{F}$ layer, F1. No significant reduction appeared in foF2 since the F2 layer is the most resilient to the loss of solar radiation. The electron density is greater in this layer and it is higher up in the Earth's atmosphere too, so it persists for much longer, even after sunset (Rishbeth and Garriott, 1969; Kelley, 1989).

For a more detailed presentation of the ionospheric structure over Athens during the eclipse day, the electron density observations were organized in altitude zones of $20 \mathrm{~km}$ from 140 to $260 \mathrm{~km}$ and the electron density variations at fixed ionospheric altitude zones are presented in Fig. 8. The time series of electron density at fixed altitudes enables the study of the electron density variations as a function of time and altitude (Altadill et al., 2001). The impact of the solar eclipse is clearly evidenced simultaneously with the time of maximum occultation over Athens, as an abrupt decrease in the electron density in all ionospheric altitudes from 140 up to 220 $\mathrm{km}$ with minimum at 10:48 UTC. By contrast, the ionization at the upper heights of the bottomside ionosphere was maintained. In addition to the general trend, consistent fluctuations are observed mainly between the first contact and the maximum occultation as special feature of the ionospheric response to the solar eclipse. These fluctuations are attributed 
to solar eclipse induced GWs propagating in the ionosphere (Zerefos et al., 2007).

\subsubsection{Gravity waves in the ionosphere}

The return of the ionospheric plasma toward a new equilibrium state, which is forced by the solar eclipse effects, is likely to be accompanied by induced wave motions excited in the neutral atmosphere that could cause significant variations in the electron and ion densities. Such oscillations were previously reported in the literature and are attributed to solar eclipse induced GWs during or after the solar eclipse (Altadill et al., 2001; Sauli et al., 2006).

In an effort to investigate the possible detection of GWs propagating in the ionosphere over Athens during this solar eclipse, ionospheric observations were first analyzed by deploying Spectral Fourier Analysis. Indeed, a 30-40 min oscillation was evident in the spectra of the Ionosonde Total Electron Content - ITEC - and in the peak electron density height in the ionosphere $-\mathrm{hmF} 2$ (Zerefos et al., 2007). The peak-to-peak amplitude of the ITEC residuals was 10$15 \%$ of the ITEC averaged over the eclipse period, while for $\mathrm{hmF} 2$ it was about $2 \%$. Cross-spectrum analysis between ionospheric and stratospheric parameters depicted high covariance in this range of periods, supporting a source of the perturbation located below the ionosphere. The electron density fluctuations (see Sect. 3.3.1) were then examined to further speculate on the main source of GWs that reached the ionospheric heights. Their amplitude increased upwards from 160 to $220 \mathrm{~km}$, which is expected for a vertically propagating wave within an atmosphere whose density decreases exponentially with altitude, while they are well attenuated above $220 \mathrm{~km}$. Their determined characteristics strengthens the argument that the source-origin of the perturbation is located below the ionospheric heights (Zerefos et al., 2007). In general, the findings of this investigation support the eclipse induced cooling of the ozone layer in the stratosphere as the main source of gravity waves propagating upwards into the ionosphere.

\subsection{Biosphere}

\subsubsection{Crops}

Various solar eclipse effects on plants mainly related to the abrupt solar light "switch off" such as transient aberrations in the chromosomal structure of root meristems and a delaying seed germination, effects on photosynthesis and evapotranspiration of crop plants, have been reported by Economou et al. (2007, references therein). In order to provide insight on the mechanisms involved in the effects of solar eclipses on photosynthesis and stomatal behavior, Economou et al. (2007) studied seven field-grown important cereal and leguminous crops.

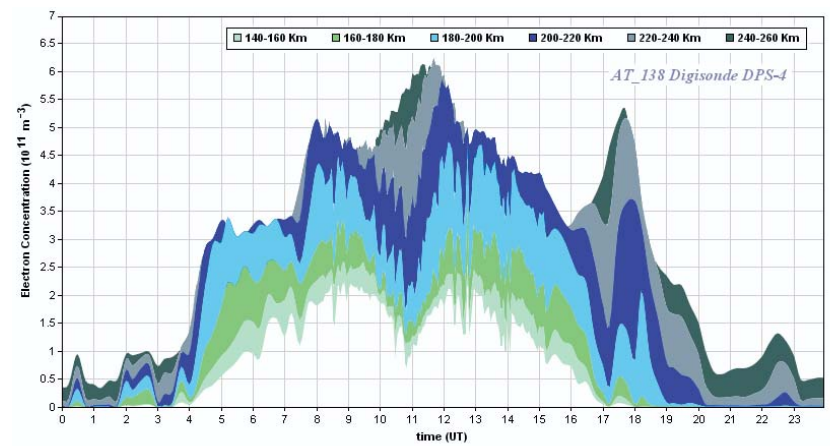

Fig. 8. Electron density variations at fixed ionospheric altitude zones from 140 to $260 \mathrm{~km}$, derived from the electron density estimations which are organized in altitude zones of $20 \mathrm{~km}$.

During the eclipse, photosynthetic rates decreased by more than a factor of 5 in some cases, in accordance with the Photosynthetic Active Radiation (PAR). The minimum photosynthetic rates reported by Economou et al. (2007) ranged between 3.13 and $10.13 \mu \mathrm{mol} \mathrm{CO} \mathrm{Cm}^{-2} \mathrm{~s}^{-1}$ for the different studied species. Comparison of the photosynthetic activity drop during the eclipse with the respective diurnal cycle showed that the effects resemble those obtained at dusk or under dense cloudiness.

The diurnal course of stomatal conductance $\left(g_{s}\right)$ followed a normal pattern for mesophytic crop species (plants with intermediate water demand), with higher values early in the day, steadily declining for the next two to three hours and remaining stable thereafter. A temporary decrease in $g_{s}$ was attributed to normal, "midday stomatal closure". Even though the most important component influencing the course of stomatal behaviour is light, Economou et al. (2007) have shown that solar irradiance was not the factor directly affecting the course of $g_{s}$ during the eclipse. They concluded that since solar irradiance attenuation has not induced stomatal closure and thus has not blocked $\mathrm{CO}_{2}$ uptake by plants, other endogenous factors should be responsible for the observed fall in photosynthetic rates. One potential factor is the much shorter duration of the processes taking place during an eclipse than the ones during dawn and dusk in the temperate climates.

\subsubsection{Marine zooplankton}

Economou et al. (2007) also studied the effects of the solar eclipse on marine zooplankton, with measurements carried out on 29 March 2006 during an oceanographic cruise, close to Kastelorizo Island (100\% eclipse magnitude). The behavior of marine populations has been investigated, separately for micro-zooplankton (ciliates) and mesozooplankton, while the change of underwater irradiance was simulated via a Hydrolight Radiative Transfer Model (Mobley, 1994). 


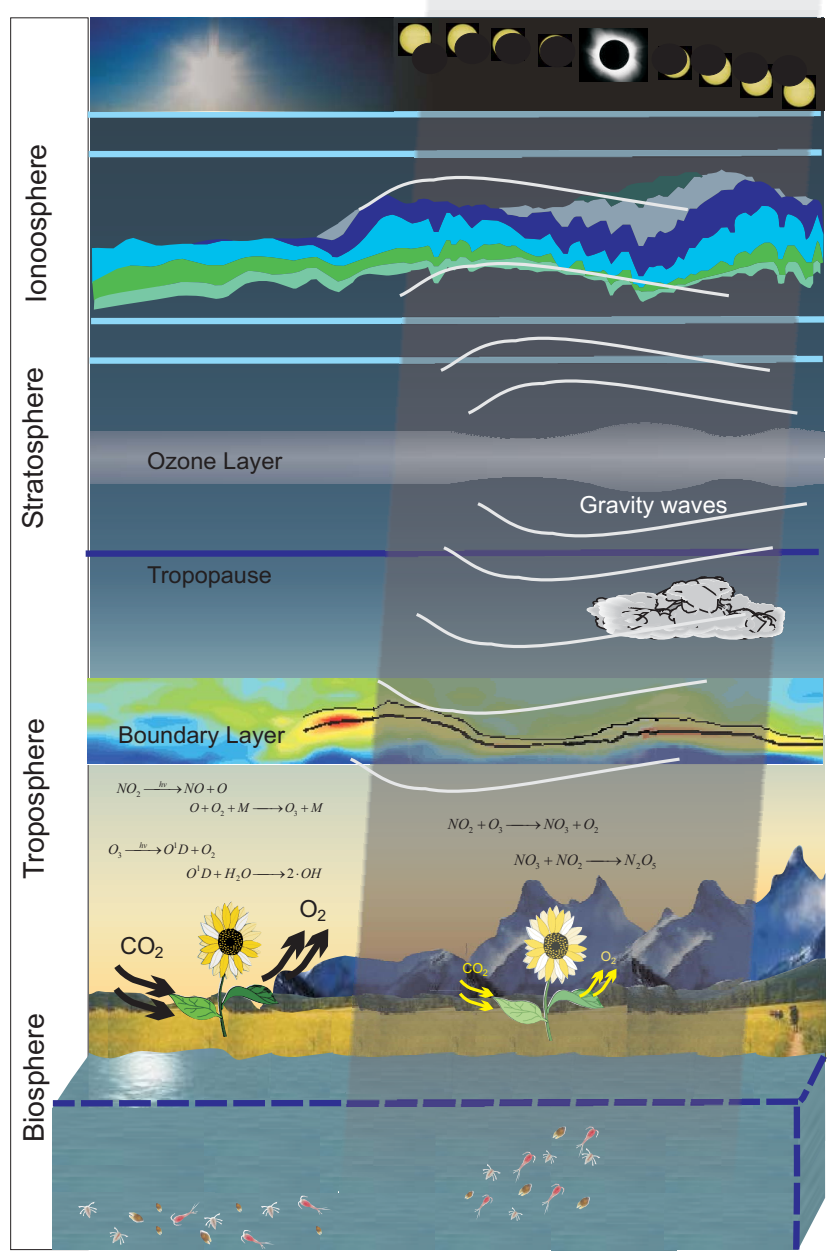

Fig. 9. Overview picture of the main solar eclipse effects on a vertically stratified environment.

Underwater profiles of temperature and salinity remained almost constant during the eclipse event. The vertical distribution of phytoplankton fluorescence (Chl- $a$ concentrations) ranged between 0.14 to $0.19 \mu \mathrm{g} \mathrm{l}^{-1}$, presented a small chlorophyll maximum between 40 and $60 \mathrm{~m}$, however no significant eclipse induced changes were observed (Economou et al., 2007). It was shown that ciliates normally tending to accumulate at $30 \mathrm{~m}$ depth, responded to the rapid decrease in light intensity during the eclipse (surface PAR had already decreased by $\sim 50 \%$ ) and adopted night-time behaviour, with a vertical homogenous spreading in the water column. From the mesozooplankton assemblage, some copepodites, having been synchronized with the exogenous changes, showed a vertical migratory movement towards the surface while other copepodites, displayed no significant differences in distribution and apparent response to the eclipse.

\section{Summary and discussion}

On the occasion of the 29 March 2006 total solar eclipse, visible over the Eastern Mediterranean, several research and academic institutes organised co-ordinated experiments to study the effects of a total solar eclipse on the environment. The scientific interest has been focused on the atmospheric response and impacts in the biosphere. The science objectives/thematic areas and the component science investigations in the current Special Issue are summarized in Table 3. The major findings based on the experimental observations and model simulations thoroughly described in the Special Issue papers and outlined in this work, are illustrated in the overview picture of the 29 March Total Solar Eclipse (Fig. 9) and highlighted below:

- Ionosphere: In the ionosphere, the impact of the solar eclipse is evidenced in the altitude range from 140 up to $220 \mathrm{~km}$, simultaneously with the time of maximum occultation. The photochemical activity decreases almost to night-time levels but also dynamical disturbances are induced. Both photochemistry and dynamics result to changes in the reflection heights and the electron concentrations, and these changes are less pronounced at higher ionospheric altitudes. Eclipse induced Gravity Waves were identified in the ionosphere, with amplitudes increasing upwards, supporting a source from below.

- Stratosphere: Even though no consistent trends are identified in total ozone column, an increase in the majority of the stations is observed, which has not however been attributed to eclipse effects. In addition, the contribution of the limb darkening effect on the artificial drop in total ozone Brewer measurements is found minor, compared to the increase of the diffuse to direct irradiance ratio. The cooling of the ozone layer in the stratosphere is experimentally shown to be the major source of Gravity Waves induced by passage of the moon's shadow from the atmosphere.

- Boundary Layer: The turbulence activity in the near surface layers of the atmosphere is suppressed causing a decrease in the Planetary Boundary Layer, similar to that during sunset hours, with a simultaneous shallow entrainment zone. These changes have been successfully simulated by Air Quality Models coupled with Weather Forecast Models.

- Meteorology: Meteorological parameters (e.g. surface temperature, wind speed) were clearly influenced by the eclipse, but were mainly controlled by local factors rather than the eclipse magnitudes. For other parameters, such as cloudiness, observations were partly masked by the synoptic conditions, not allowing stable conclusions. 
Table 3. Science objectives/thematic areas and the component publications in the current Special Issue.

\begin{tabular}{ll}
\hline Thematic Areas - Eclipse Impacts on ... & ACP Special Issue Component \\
\hline Synoptic and Boundary Layer Meterology & Founda et al. (2007) \\
& Amiridis et al. (2007) \\
Atmospheric Chemistry, Air Quality & Zanis et al. (2007) \\
& Tzanis et al. (2008) \\
Solar Radiation & Emde et al. (2007) \\
& Kazadzis et al. (2007) \\
& Kazantzidis et al. (2007) \\
& Psiloglou et al. (2007) \\
Ionosphere & Gerasopoulos et al. (2008) Overview \\
Gravity Waves & Zerefos et al. (2007) \\
Ecosystems (Crops, Marine) & Economou et al. (2008) \\
\hline
\end{tabular}

- Photochemistry: During the eclipse the photochemistry of the atmosphere changed, and mainly night time chemistry dominated. The higher the levels of pollution the more pronounced the changes have been. Both, 3-D Air Quality and box models were able to simulate the chemical response of the atmosphere, as compared to in situ measurements.

- Crops: In the biosphere, and in particular in the crops, it is found that various species respond differently to the induced changes in solar radiation, allowing the use of certain species as indices for future climate changes. It is also shown that solar irradiance attenuation has caused endogenous disorder to the plants rather than dynamical (e.g. no stomatal closure as during the night), influencing their photosynthetic efficiency.

- Marine: Most underwater populations (e.g. zoonplankton) in general reacted and synchronised to the exogenous changes in radiation. The rate and the intensity of their reaction once more varied between different species.

This work constitutes an excellent example of multidisciplinary co-operation that has brought together people with different background and infrastructure, towards a common goal: to understand environmental responses to abrupt exogenous disturbances. All acquired results as well as questions that have not been answered or problems that have emerged during the experiments, for example the difficulties of identifying Gravity Waves in the troposphere or the chemical processes inside plants that control their photosynthetic rates, should be taken into account for planning of solid, integrated experiments in the future. A number of different type of models such as air quality, meteorological, radiative transfer, have been evaluated under the conditions induced by the solar eclipse for different environments, and they can be used for similar situations in the future.
Acknowledgements. Part of this study has been facilitated by the ACCENT Network. We are grateful to the Hellenic National Meteorological Service (HNMS), the Laboratory of Meteorology \& Climatology of the Aristotle University of Thessaloniki and the Environmental Services Department of the Athens International Airport for providing meteorological, air quality and radiosonde data. Maps were created using Google Earth with solar eclipse path add-ons from Xavier M. Jubier (http://xjubier.free.fr/en/site_pages/Solar_Eclipses.html, Eclipse Predictions by Fred Espenak, NASA's GSFC). The authors would like to thank the MODIS science data support team for providing raw images and Dr. A. Retalis for processing of satellite images. EG would like to thank S. Kazadzis for helpful conversations regarding radiation issues. The crew of the oceanographic $R / V$ AEGAIO and all scientific and technical staff from the participating institutions that have organised the individual experimental campaigns are kindly acknowledged.

Edited by: N. Mihalopoulos

\section{References}

Abram, J. P., Creasey, D. J., Heard, D. E., Lee, J. D., and Pilling, M. J.: Hydroxyl radical and ozone measurements in England during the solar eclipse of 11 August 1999, Geophys. Res. Lett., 27(D21), 3437-3440, 2000.

Altadill, D., Sole, J. G., and Apostolov, E. M.: Vertical structure of a gravity wave like oscillation in the ionosphere generated by the solar eclipse of 11 August 1999, J. Geophys. Res., 106(A10), 21 419-21 428, 2001.

Amiridis, V., Melas D., Balis, D. S., Papayannis, A., Founda, D., Katragkou, E., Giannakaki, E., Mamouri, R. E., Gerasopoulos, E., and Zerefos, C.: Aerosol lidar observations and model calculations of the planetary boundary layer evolution over Greece, during the March 2006 total solar eclipse, Atmos. Chem. Phys., 7, 6181-6189, 2007, http://www.atmos-chem-phys.net/7/6181/2007/. 
Anderson, R. C., Keefer, D. R., and Myers, O. E.: Atmospheric pressure and temperature changes during the 7 March 1970 solar eclipse, J. Atmos. Sci., 29, 583-587, 1972.

Anderson, J.: Meteorological changes during a solar eclipse, Weather, 54(7), 207-215, 1999.

Antonia, R. A., Chambers, A. J., Phong-Anant, D., Rajagopalan, S., and Sreenivasan, K. R.: Response of atmospheric surface layer turbulence to a partial solar eclipse, J. Geophys. Res., 4, 1689$1692,1979$.

Aplin, K. L. and Harrison, R. G.: Meteorological effects of the eclipse of 11 August 1999 in cloudy and clear conditions, Proc. R. Soc. Lond. A, 459, 353-372, doi:10.1098/rspa.2002.1042, 2002

Baran, L. W., Ephishov, I. I., Shagimuratov, I. I., Ivanov, V. P., and Lagovsky, A. F.: The response of the ionospheric total electron content to the solar eclipse on 11 August 1999, Adv. Space Res., 31, 4, 989-994, 2003.

Beynon W. J. G and Brown, G. M.: Literature on Solar Eclipses and the Ionosphere in Solar Eclipses and the Ionosphere, Pergamon Press, London, 1956.

Bojkov, R. D.: The ozone variations during the solar eclipse of 20 May 1966, Tellus, 20, 417-421, 1968.

Chakrabarty, D. K., Shah, N. C., and Pandya, K. V.: Fluctuation in ozone column over Ahmedabad during the solar eclipse of 24 October 1995, Geophys. Res. Lett., 24(23), 3001, 1997.

Chandra, H., Vyas, G. D., and Sharma, S.: Ionospheric effects of the total solar eclipse of 24 October 1995, over Ahmedabad, Ind. J. of Radio \& Space Phys., 26, 30-35, 1997.

Chimonas, G.: Internal gravity-wave motions induced in the Earth's atmosphere by a solar eclipse, J. Geophys. Res., 75, 5545-5551, 1970.

Deen, J. L. and Bruner, M. H.: The effect of the 1932 eclipse upon the width of stomatal openings in gray birch, Ecology, 14, 76-77, 1933.

Dyson, F. W., Eddington, A. S., and Davidson C.: A determination of the deflection of light by the Sun's gravitational field, from observations made at the total eclipse of 29 May 1919, Philos. Trans. Royal Soc. London, 220(A), 291-333, 1920.

Eaton, F. D., Hines, J. R., Hatch, W. H., Cionco, R. M., Byers, J., Garvey, D., and Miller, D. R.: 10 Solar eclipse effects observed in the planetary boundary layer over a desert, Bound.-Lay. Meteorol., 83, 331-346, 1997.

Eckermann, S. D., Broutman, D., Stollberg, M. T., Ma, J., McCormack, J. P., and Hogan, T. F.: Atmospheric effects of the total solar eclipse of 4 December 2002 simulated with a high-altitude global Model, J. Geophys. Res., 112, D14105, doi:10.1029/2006JD007880, 2007.

Economou, G., Christou, E. D., Giannakourou, A., Gerasopoulos, E., Georgopoulos, D., Kotoulas, V., Lyra, D., Tsakalis, N., Tzortziou, M., Vahamidis, P., Papathanassiou, E., and Karamanos, A.: Eclipse effects on field crops and marine zooplankton: the 29 March 2006 total solar eclipse, Atmos. Chem. Phys., 8, 4665-4676, 2008,

http://www.atmos-chem-phys.net/8/4665/2008/.

Emde, C. and Mayer, B.: Simulation of solar radiation during a total eclipse: a challenge for radiative transfer Atmos. Chem. Phys., 7, 2259-2270, 2007

Espenak, F. and Anderson, J.: Total Solar Eclipse of 2006 March 29, NASA/TP-2004-212762, 74 pp., 2004.
Fernandez, W., Castro, V., and Hidalgo, H.: Air temperature and wind changes in Costa Rica during the total solar eclipse of 11 July 1991, Earth, Moon and Planets, 63, 133-147, 1993.

Fernandez, W., Hidalgo, H., Coronel, G., and Morales, E.: Changes in meteorological variables 15 in Coronel Oviedo, Paraguay, during the total solar eclipse of 3 November 1994, Earth, Moon and Planets, 74, 49-59, 1996.

Founda, D., Melas, D., Lykoudis, S., Lisaridis, I., Gerasopoulos, E., Kouvarakis, G., Petrakis, M., and Zerefos, C.: The effect of the total solar eclipse of 29 March 2006 on meteorological variables in Greece, Atmos. Chem. Phys., 7, 5543-5553, 2007, http://www.atmos-chem-phys.net/7/5543/2007/.

Gerasopoulos, E., Andreae, M. O., Zerefos, C. S., Andreae, T. W., Balis, D., Formenti, P., Merlet, P., Amiridis, V., and Papastefanou, C.: Climatological aspects of aerosol optical properties in Northern Greece, Atmos. Chem. Phys., 3, 2025-2041, 2003, http://www.atmos-chem-phys.net/3/2025/2003/.

Gerasopoulos, E., Kouvarakis, G., Vrekoussis, M., Kanakidou, M., and Mihalopoulos, N.: Ozone variability in the marine boundary layer of the Eastern Mediterranean based on 7-year observations, J. Geophys. Res., 110, D15309, doi:10.1029/2005JD005991, 2005.

Gerasopoulos, E., Kouvarakis, G., Vrekoussis, M., Donoussis, C., Kanakidou, M., and Mihalopoulos, N.: Photochemical ozone production in the Eastern Mediterranean, Atmos. Environ., 40, 3057-3069, doi:10.1016/j.atmosenv.2005.12.061, 2006a.

Gerasopoulos, E., Kouvarakis, G., Babasakalis, P., Vrekoussis ,M., Putaud, J. P., and Mihalopoulos, N.: Origin and variability of particulate matter $\left(\mathrm{PM}_{10}\right)$ mass concentrations over the eastern Mediterranean, Atmos. Environ., 40, 4679-4690, doi:10.1016/j.atmosenv.2006.04.020, 2006b.

Gralton, E. and Line, C.: Eclipse of the sun, August 1999: a psychiatric perspective, Psychiatr. Bull., 23, 500-502, 1999.

Hanna, E.: Meteorological effects of the solar eclipse of $11 \mathrm{Au}-$ gust 1999, Weather, 55, 430-446, 2000.

Hanuise, C., Broche, P., and Ogubazghi, G.: HF Doppler observations of gravity waves during the 16 February 1980 solar eclipse, J. Atmos. Solar-Terr. Phys., 44, 963-966, 1982.

Jones, B. W.: A search for atmospheric pressure waves from the total solar eclipse of 9 March 1997, J. Atmos. Solar-Terr. Phys., 61, 1017-1024, 1999.

Kawabata, Y.: Spectrographic observation on the amount of ozone at the total solar eclipse of 15 February 1961, J. Astron. Geophys., 14, 1-3, 1937.

Kazadzis, S., Bais, A., Kouremeti, N., Blumthaler, M., Webb, A., Kift, R., Schallhart, B., and Kazantzidis, A.: Effects of total solar eclipse of 29 March 2006 on surface radiation, Atmos. Chem. and Phys., 7, 5775-5783, 2007.

Kazantzidis, A., Bais, A. F., Emde, C., Kazadzis, S. and Zerefos, C. S.: Attenuation of global ultraviolet and visible irradiance over Greece during the total solar eclipse of 29 March 2006, Atmos. Chem. and Phys., 7, 5959-5969, 2007.

Kelley, M. C.: The Earth's Ionosphere: Plasma Physics and Electrodynamics, Academic Press, San Diego, 1989.

Klobuchar J. A. and Whitney, H. E.: Ionospheric electron content measurements during a Solar Eclipse, J. Geophys. Res., 70, 1254, 1965.

Kolev, N., Tatarov, B., Grigorieva, V., Donev, E., Simenonov, P., Umlensky, V., Kaprielov, B., and Kolev, I.: Aerosol Lidar and in 
situ ozone observations of the planetary boundary layer over Bulgaria during the solar eclipse of 11 August 1999, Int. J. Remote Sens., 26, 3567-3584, 2005.

Kondratyev, K. Y. and Varotsos, C.: Remote sensing and global tropospheric ozone observed dynamics, Int. J. Remote Sens., 23(1), 159-178, 2002.

Köpke, P., Reuder, J., and Schween, J.: Spectral variation of the solar radiation during an eclipse, Meteorol Z, 10(3), 179-186, 2001.

Kourtidis, K., Zerefos, C. S., Rapsomanikis, V., Simeonov, D., Balis, P. E., Perros, A. M., Thompson, J., Witte, B., Calpini, W. M., Sharobiem, A., Papayannis, A., Mihalopoulos, N., and Drakou, R.: Regional levels of ozone in the troposphere over the eastern Mediterranean, J. Geophys. Res., 107(D18), 8140, doi:10.1029/2000JD000140, 2002.

Kouvarakis, G., Vrekousis, M., Mihalopoulos, N., Kourtidis, K., Rappengluck, B., Gerasopoulos, E., and Zerefos, C. S.: Spatial and temporal variability of tropospheric ozone (O3) in the boundary layer above the Aegean Sea (Eastern Mediterranean), J. Geophys. Res.-Atmos., 107, 8141, doi:10.1029/2000JD000081, 2002.

Mayaud, P. N.: Derivation, Meaning and Use of Geomagnetic Indices, AGU Geophysical Monograph, 22, Washington D.C., 1980.

Mims III, F. M. and Mims, E. R.: Fluctuations in column ozone during the total solar eclipse of 11 July 1991, Geophys. Res. Lett., 20(5), 367-370, 1993.

Mobley, C. D.: Light and Water: Radiative Transfer in Natural Waters. Academic Press, San Diego, Calif., 1994.

Papayannis, A., Balis, D., Bais, A. F., Van der Bergh, H., Calpini, B., Durieux, E., Fioranni, L., Jaquet, L., Ziomas, I. C., and Zerefos, C. S.: Role of Urban and Suburban Aerosols on Solar UV Radiation Over Athens, Greece, Atmos. Environ., 32(12), 2193 2201, 1998.

Psiloglou, B. E. and Kambezidis, H. D.: Performance of the meteorological radiation model during the solar eclipse of 29 March 2006, Atmos. Chem. Phys., 7, 6047-6059, 2007, http://www.atmos-chem-phys.net/7/6047/2007/.

Rishbeth H. and Garriott, O. K.: Introduction to Ionospheric Physics, Academic Press, New York and London, 1969.

Sauli, P., Abry, P., Boska, J., and Duchayne, L.: Wavelet characterization of ionospheric acoustic and gravity waves occurring during the solar eclipse of 11 August 1999, J. Atmos. Solar-Terr. Phys., 68, 586-598, 2006.

Segal, M., Turner, R.W., Prusa, J., Bitzer, R.J., and Finley, S. V.: Solar eclipse effect on shelter air temperature, Bull. Am. Meteorol. Soc., 77, 89-99, 1996.

Seykora, E. J., Bhatnagar, A., Jain, R. M., and Streete, J. L.: Evidence of atmospheric gravity waves produced during the 11 June 1983 total solar eclipse, Nature, 313, 124-125, 1985.

Sharp, W. E., Silverman, S. M., and Lloyd, J. W. F.: Summary of sky brightness measurements during eclipses of the sun, Appl. Opt., 10, 1207-1210, 1971.

Silverman, S. M. and Mullen, E. G.: Sky brightness during eclipses: a review, Appl. Optics, 14, 2838-2843, 1975.

Singh, L., Tyagi, T. R., Somayajulu, Y. V., Vijayakumar, P. N., Dabas, R. S., Loganadham, B., Ramakrishna, S., Rama Rao, P. V. S., Dasgupta, A., Naneeth, G., Klobuchar, J. A., and Hartmann, G. K.: A multi-station satellite radio beacon study of ionospheric variations during solar eclipses, J. Atmos. Solar-Terr. Phys., 51, 271-278, 1989.

Srivastava, G. P., Pakkir, M. P. M., and Balwalli, R. R.: Ozone concentration measurements near the ground at Raichur during the solar eclipse of 1980, Proceedings of Indian Natural Sciences Academy, A48(3), 138-142, 1982.

Stranz, D.: Ozone measurements during solar eclipse, Tellus, 13, 276-279, 1961.

Tzanis, C., Varotsos, C., and Viras, L.: Impacts of the solar eclipse of 29 March 2006 on the surface ozone concentration, the solar ultraviolet radiation and the meteorological parameters at Athens, Greece, Atmos. Chem. Phys., 8, 425-430, 2008, http://www.atmos-chem-phys.net/8/425/2008/.

Varotsos, C., Alexandris, D., Chronopoulos, G., Tzanis, C.: Aircraft observations of the solar ultraviolet irradiance throughout the troposphere, J. Geophys. Res.-Atmos., 106(D14), 14 843-14 854, 2001.

Voracek, M., Fisher, M. L., and Sonneck, G.: Solar Eclipse and Suicide, Letter to the Editor, Am. J. Psychiatry, 159, 1247-1248, 2002.

Vrekoussis, M., Liakakou, E., Mihalopoulos, N., Kanakidou, M., Crutzen, P. J., and Lelieveld, J.: Formation of $\mathrm{HNO}_{3}$ and $\mathrm{NO}_{3}$ in the anthropogenically-influenced eastern Mediterranean marine boundary layer, Geophys. Res. Lett., 33, L05811, doi:10.1029/2005GL025069, 2006.

Vrekoussis, M., Mihalopoulos, N., Gerasopoulos, E., Kanakidou, M., Crutzen, P. J., and Lelieveld, J.: Two-years of NO3 radical observations in the boundary layer over the Eastern Mediterranean, Atmos. Chem. Phys., 7, 315-327, 2007

Wong, S. C., Eke, T., and Ziakas, N. G.: Eclipse burns: a prospective study of solar retinopathy following the 1999 solar eclipse, Lancet, 357, 199-200, 2001.

Zanis P., Zerefos, C. S., Gilge, S., Melas, D., Balis, D., Ziomas, I., Gerasopoulos, E., Tzoumaka, P., Kaminski, U., Fricke, W.: Comparison of measured and modelled surface ozone concentrations at two different sites in Europe during the solar eclipse on 11 August 1999, Atmos. Environ., 35, 4663-4673, 2001.

Zanis, P., Katragkou, E., Kanakidou, M., Psiloglou, B. E., Karathanasis, S., Vrekoussis, M., Gerasopoulos, E., Lysaridis, I, Markakis, K., Poupkou, A., Amiridis, V., Melas, D., Mihalopoulos, N., and Zerefos, C.: Effects on surface atmospheric photooxidants over Greece during the total solar eclipse event of 29 March 2006, Atmos. Chem. Phys., 7, 6061-6073, 2007, http://www.atmos-chem-phys.net/7/6061/2007/.

Zerefos, C., Meleti, C., Balis, D., Tourpali, K., Bais, A. F.: Quasibiennial and longer-term changes in clear sky UV-B solar irradiance, Geophys. Res. Lett., 25(23), 4345-4348, 1998.

Zerefos, C. S, Balis, D. S., Meleti, C., Bais, A. F., Tourpali, K., Vanicek, K., Cappelani, F., Kaminski, U., Tiziano, C., Stubi, R., Formenti, P., and Andreae, A.: Changes in environmental parameters during the solar eclipse of 11 August 1999, over Europe. Effects on surface UV 20 solar irradiance and total ozone, J. Geophys. Res., 105(D21), 26 463-26473, 2000.

Zerefos, C. S., Balis, D. S., Zanis, P., Meleti, C., Bais, A. F., Tourpali, K., Melas, D., Ziomas, I., Galani, E., Kourtidis, K., Papayannis, A., and Gogosheva, Z.: Changes in surface UV solar irradiance and ozone over the Balkans during the eclipse of 11 August 1999,Adv. Space Res., 27(12), 1955-1963, 2001. 
Zerefos, C. S., Gerasopoulos, E., Tsagouri, I., Psiloglou, B. E., Belehaki, A., Herekakis, T., Bais, A., Kazadzis, S., Eleftheratos, C., Kalivitis, N., and Mihalopoulos, N.: Evidence of gravity waves into the atmosphere during the March 2006 total solar eclipse, Atmos. Chem. Phys., 7, 4943-4951, 2007, http://www.atmos-chem-phys.net/7/4943/2007/.

Zirker, J. B.: Total Eclipses of the Sun, Princeton University Press, 1995. 